\title{
APLIKASI ANDROID PEMBELAJARAN HURUF HIJAIYAH BESERTA TANDA BACANYA PADA TK AR RAIHAN
}

\author{
Irfan Ismunandar ${ }^{1}$, Rudi Prasetya ${ }^{2}$, Nunu Kustian ${ }^{3}$ \\ Program Studi Teknik Informatika, Fakultas Teknik dan Ilmu Komputer \\ Universitas Indraprasta PGRI \\ Jalan Raya Tengah No 80, Kelurahan Gedong, Pasar Rebo, Jakarta Timur \\ Irfan.ismunandar@gmail.com ${ }^{1}$, rudiprasetya1@gmail.com² ${ }^{2}$ kustiannunu@gmail.com³
}

\begin{abstract}
Abstrak
Rancangan penelitian ini adalah untuk membuat aplikasi pembelajaran pengenalan huruf hijaiyah untuk membantu mengembangkan minat para murid dalam mempelajari bahasa arab. dengan menggunakan menggunakan aplikasi ini maka guru akan mudah mengajari murid muridnya karena terdapat suara di dalam aplikasi tersebut. metodologi pengembangan sistem yang digunakan merupakan metodologi waterfall, metode waterfall dimulai dengan spesifikasi kebutuhan pengguna lalu berlanjut melalui tahapan-tahapan perencanaan, permodelan, konstruksi, serta penyerahan sistem ke para pelanggan / pengguna, yang diakhiri dengan dukungan pada perangkat lunak lengkap yang dihasilkan. Pada pengujian aplikasi pembelajaran terdapat kuisioner. Dan peneliti menarik kesimpulan bahwa dengan pembelajaran yang masih konvensional berubah menjadi aplikasi yang dapat mempermudah dalam belajar, menambahkan minat murid dalam belajar dan menjadikan efektif dalam belajar.
\end{abstract}

Kata Kunci: Android, Aplikasi Pembelajaran, Huruf Hijaiyah

\begin{abstract}
The design of this study was to create a Hijaiyah letter recognition learning application to help develop students' interest in learning Arabic. by using this application, the teacher will easily teach his students because there is a sound in the application. The system development methodology used is the waterfall methodology, the waterfall method starts with the specification of user needs and then continues through the stages of planning, modeling, construction, and submitting the system to customers or users, which ends with support for the complete software produced. In testing the learning application there is a questionnaire. And the researchers concluded that with conventional learning turning into application that can facilitate learning adding students' interest in learning and making effective in learning.
\end{abstract}

\section{Keywords: Android, Hijaiyah alphabet, Learning application}

\section{PENDAHULUAN}

Saat ini anak anak kurang minat terhadap pembelajaran huruf hijaiyah atau membaca Al Qur'an karena dengan adanya internet kita harus mengarahkan anak anak untuk belajar menggunakan internet dengan memberikan pembelajaran agama Islam untuk anak usia dini sebagai sarana pembuatan karakter anak. Rumusan masalah yaitu bagaimana merancang aplikasi belajar huruf hijaiyah pada smartphone android yang mudah digunakan, dimengerti dan mempunyai tampilan yang menarik. Tujuan dari penelitian ini untuk membuktikan keefektifan penggunaan aplikasi dalam belajar huruf hijaiyah beserta tanda bacanya pada Tk Ar Raihan, untuk mengetahui kemampuan murid dalam membaca huruf hijaiyah dan tanda bacanya, untuk mengetahui kemampuan murid dalam mengingat huruf huruf hijaiyah beserta tanda bacanya.

Pembuatan aplikasi yang peneliti lakukan ini diharapkan memberikan manfaat secara teoritis maupun praktis. Secara teoritis dapat menambah khazanah keilmuan mengenai pembelajaran pengenalan huruf hijaiyah beserta tanda bacanya pada anak usia dini. Secara praktis bagi peserta didik akan mendapatkan kemudahan dalam belajar iqro yang tentunya akan mendapat dampak positif. Sedangkan bagi orang tua dan guru dapat digunakan sebagai bahan pertimbangan dalam menentukan media pembelajaran yang menarik untuk melatih kemampuan belajar huruf hijaiyah pada anak usia dini. 


\section{PENELITIAN RELEVAN}

Penelitian oleh (Nurfuadi, 2017) yang berjudul Rancang Bangun Media Pembelajaran Pengenalan Budaya Indonesia Berbasis Android Menggunakan Phonegap. Latar belakang dari penelitian tersebut adalah anak anak yang kurang mengenal budaya apa saja yang terdapat di Indonesia, dan tujuan dari aplikasi yang dibuat adalah agar dapat memudahkan anak anak atau penggunanya untuk mengetahui informasi tentang budaya untuk kategori tarian, lagu, rumah, pakaian, alat musik, dan senjata tradisional.

Penelitian oleh (Cantika, 2017) yang berjudul Rancang Bangun Aplikasi E-Learning Untuk Pembelajaran Agama Islam Berbasis Android. Latar belakang dari penelitian tersebut menunjukan bahwa pembelajaran e-learning ini membawa pengaruh dari proses belajar konfensional kedalam bentuk digital baik secara isi (content) dan sistemnya. Tujuan dari aplikasi yang dibuat merupakan sebagai sarana penunjang pendidikan dalam mempelajari agama islam untuk anak usia dini, karena aplikasi ini menampilkan materi pembelajaran seperti tatacara wudhu, sholat, nama-nama malaikat beserta tugasnya, rukun Islam, rukun iman, angka arab, huruf arab, bulan-bulan Islam, serta namanama nabi.

\section{METODE PENELITIAN}

Metodologi pengembangan sistem yang akan digunakan adalah Waterfall, metode waterfall sering dinamakan siklus hidup klasik (classic life cycle), metode waterfall dimulai dengan spesifikasi kebutuhan pengguna lalu berlanjut melalui tahapan-tahapan perencanaan (planning), permodelan (modeling), konstruksi (construction), serta penyerahan sistem ke para pelanggan/pengguna (deployment), yang diakhiri dengan dukungan pada perangkat lunak lengkap yang dihasilkan (Pressman, 2012). Tahapan metode waterfall dapat dilihat pada gambar di bawah ini.

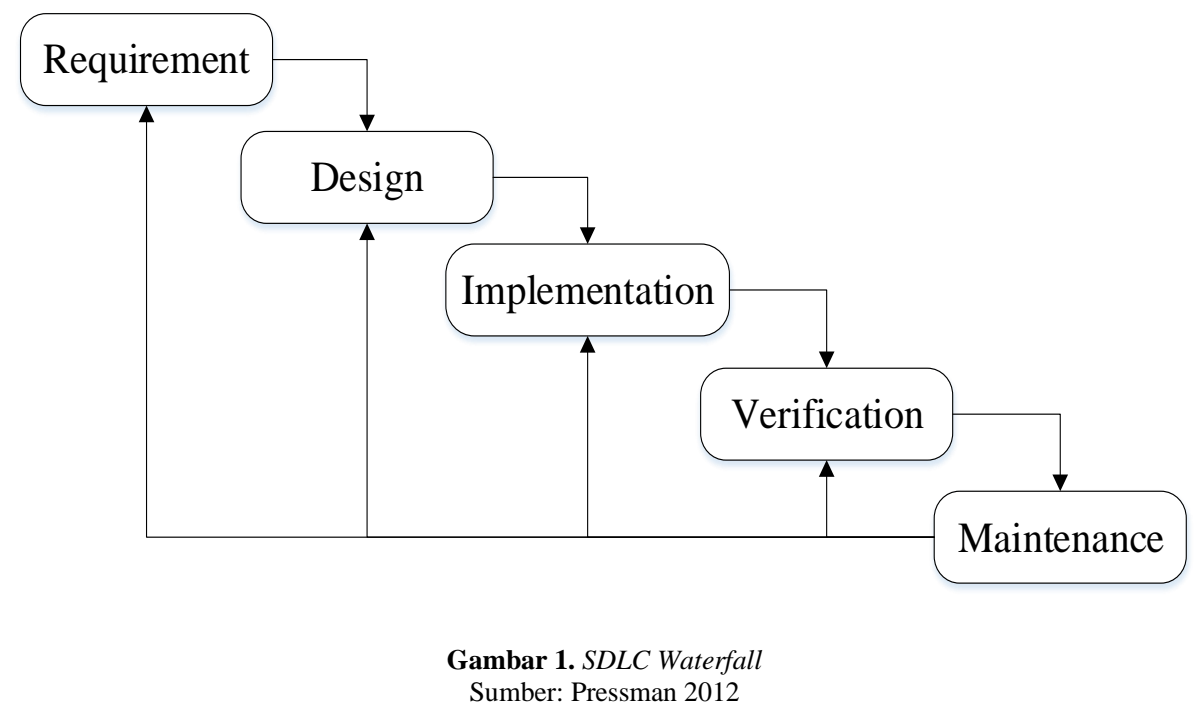

Berikut adalah penjelasan dari tahapan-tahapan yang terdapat dalam model Waterfall:

1. Requirement Analisis

Tahap ini pengembang sistem diperlukan komunikasi yang bertujuan untuk memahami perangkat lunak yang diharapkan oleh pengguna dan batasan perangkat lunak tersebut. Informasi ini biasanya dapat diperoleh melalui wawancara, diskusi atau survei langsung. Informasi dianalisis untuk mendapatkan data yang dibutuhkan oleh pengguna.

2. System Design

Spesifikasi kebutuhan dari tahap sebelumnya akan dipelajari dalam fase ini dan desain sistem disiapkan. Desain Sistem membantu dalam menentukan perangkat keras (hardware) dan sistem persyaratan dan juga membantu dalam mendefinisikan arsitektur sistem secara keseluruhan.

2. Implementation

Pada tahap ini, sistem pertama kali dikembangkan di program kecil yang disebut unit, yang terintegrasi dalam tahap selanjutnya. Setiap unit dikembangkan dan diuji untuk fungsionalitas yang disebut sebagai unit testing. 
3. Integration \& Testing

Seluruh unit yang dikembangkan dalam tahap implementasi diintegrasikan ke dalam sistem setelah pengujian yang dilakukan masing-masing unit. Setelah integrasi seluruh sistem diuji untuk mengecek setiap kegagalan maupun kesalahan.

4. Operation \& Maintenance

Tahap akhir dalam model waterfall. Perangkat lunak yang sudah jadi, dijalankan serta dilakukan pemeliharaan. Pemeliharaan termasuk dalam memperbaiki kesalahan yang tidak ditemukan pada langkah sebelumnya. Perbaikan implementasi unit sistem dan peningkatan jasa sistem sebagai kebutuhan baru.

Tahapan penelitian :

1. Mengadakan wawancara kepada pihak yang terkait, yang awalnya dapat bertatap muka dan tanya jawab secara langsung namun sejak covid-19 peneliti melakukan wawancara menggunakan aplikasi whatsapp dengan pemilik TK.

2. Peneliti mengadakan kunjungan langsung ke TK Ar Raihan untuk memperoleh data secara akurat dan memperoleh gambaran sistem berjalan yang tepat, akan tetapi sejak covid-19 peneliti datang ke TK Ar Raihan dengan mematuhi protokol PSBB yang dijalankan oleh pemerintah.

3. Peneliti juga melakukan studi kepustakaan dengan menggunakan buku yang dapat dijadikan referensi dan juga internet, guna menunjang informasi yang dibutuhkan dalam penelitian ini.

\title{
HASIL DAN PEMBAHASAN
}

Untuk menyelesaikan masalah yang ada, maka dari itu peneliti memberikan solusi agar dalam kegiatan proses mengajar efektik dan menjadikan daya Tarik murid untuk ingin memahami dan rasa ingin tau apa materi yang harus dipelajari dari pengenalan huruf hijaiyah, tanda bacanya, serta pelafalannya yang akan di pelajari lewat smartphone, menjadikan siswa akan lebih terfokus dalam pendidikannya. Berikut merupakan flowchart dari sistem yang di usulkan :

\section{Flowchart Menu Utama}

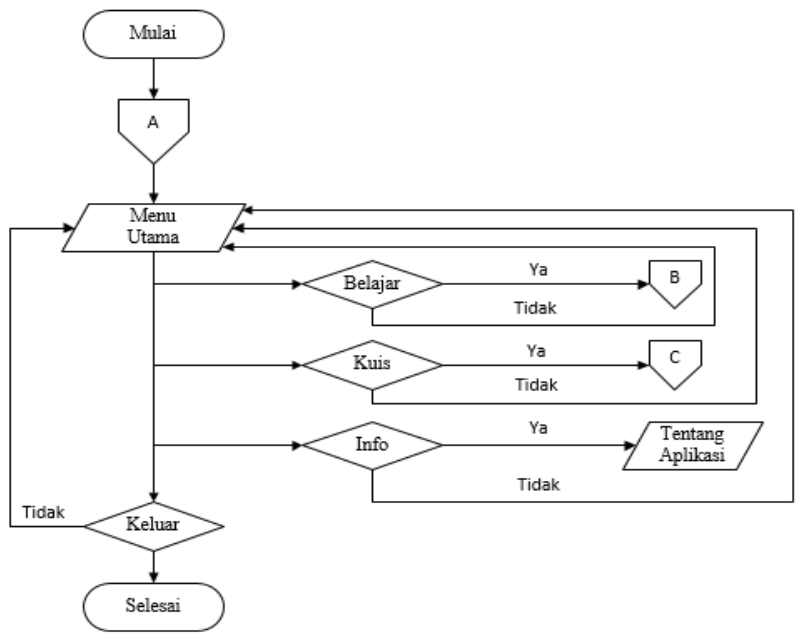

Gambar 2. Flowchart login

\section{Pseucode}

\author{
MenuUtama.create(); \\ Belajar.create(); \\ IF Belajar.clicked() \\ THEN Belajar.Start(); \\ ELSE IF Belajar.notclicked() \\ THEN MenuUtama.Start(); \\ END IF \\ InfoAplikasi.create(); \\ IF InfoAplikasi.clicked() ;
}


THEN InfoAplikasi.Start();

ElSE.IF InfoAplikasi,notclicked()

THEN MenuUtama.Start();

END IF

Kuis.create();

IF Kuis.clicked()

THEN Kuis.Start();

ELSE IF Kuis.notclicked()

THEN MenuUtama.Start();

END IF

END

\section{Flowchart Menu Belajar}

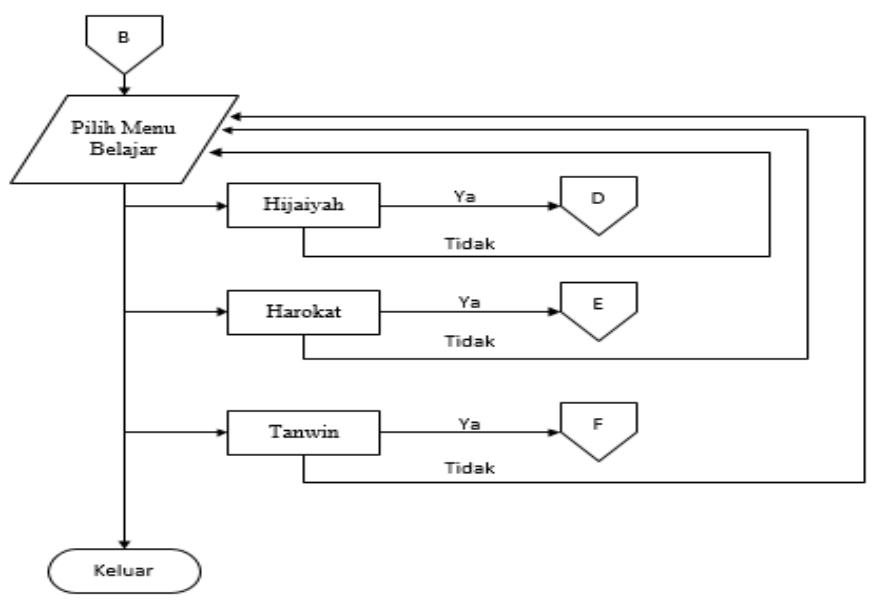

Gambar 3. Flowchart Menu Belajar

\section{Pseucode}

MenuBelajar.create(); Hijaiyah.create();

IF Hijaiyah.clicked()THEN Hijaiyah.Start();

ELSE IF Hijaiyah.notclicked()

THEN MenuBelajar.Start();

END IF Harokat.create();

IF Harokat.clicked() THEN Harokat.Start();

ELSE IF Harokat.notclicked()

THEN MenuBelajar.Start();

END IF IF Tanwin.clicked()

THEN Tanwin.Start();

ELSE IF Tanwin.notclicked()

THEN MenuBelajar.Start();

END IF END

\section{Flowchart Menu Kuis}




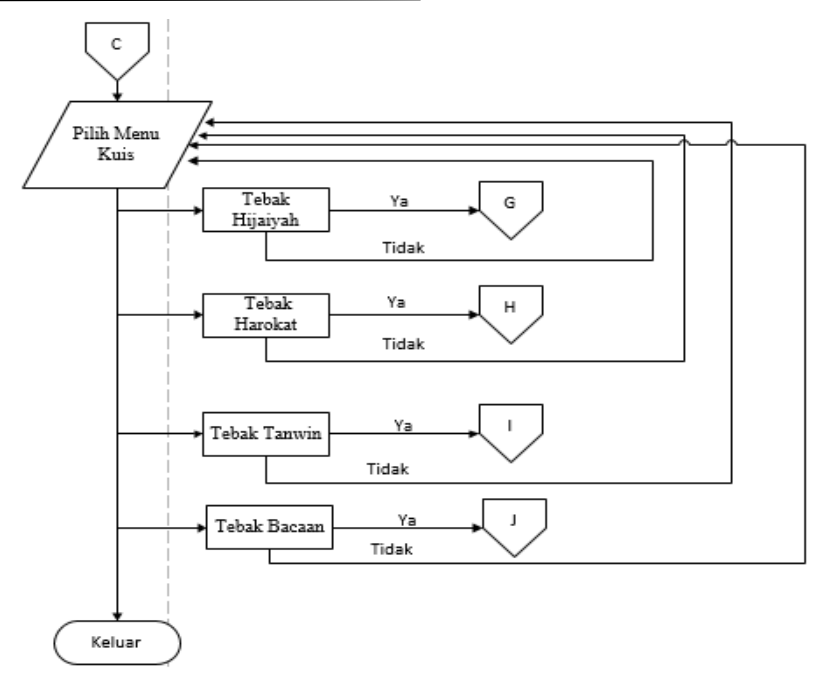

Gambar 4. Flowchart Menu Kuis

\title{
Pseucode
}

\author{
MenuKuis.create(); \\ TebakHijaiyah.create(); \\ IFTebakHijaiyah.clicked() \\ THEN \\ TebakHijaiyah.Start(); \\ ELSE IF \\ TebakHijaiyah.notclicked() \\ THEN \\ MenuKuis.Start(); \\ END IF \\ TebakHarokat.create(); \\ IF Tebak TebakHarokat.clicked() \\ THEN \\ Tebak TebakHarokat.Start(); \\ ELSE IF \\ Tebak TebakHarokat.notclicked() \\ THEN MenuKuis.Start(); \\ END IF \\ TebakTanwin.create(); \\ IF Tebak TebakTanwin.clicked() \\ THEN Tebak TebakTanwin.Start(); \\ ELSE IF Tebak TebakTanwin.notclicked() \\ THEN MenuKuis.Start(); END IF \\ TebakBacaan.create(); \\ IF \\ Tebak TebakBacaan.clicked() \\ THEN \\ Tebak TebakBacaan.Start(); \\ ELSE IF \\ Tebak TebakBacaan.notclicked() \\ THEN \\ MenuKuis.Start(); \\ END IF END.
}

\section{Tampilan Aplikasi}




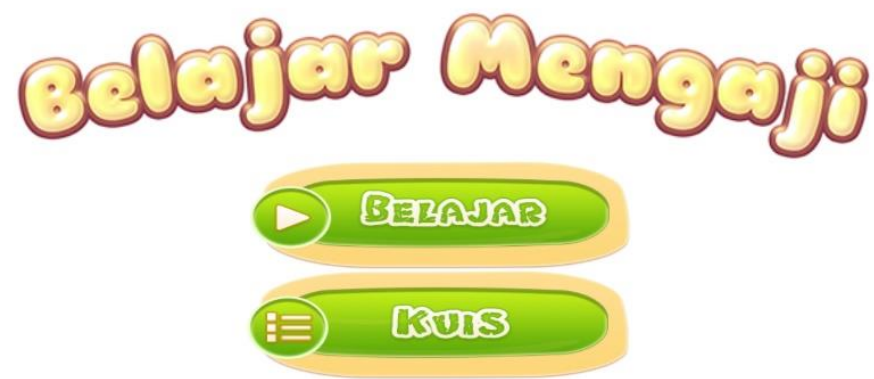

Pada Gambar 5 menampilkan Menu Belajar untuk memilih menu yang di inginkan pada menu utama terdapat dua menu yaitu menu belajar dan menu kuis.


Gambar 6. Tampilan Menu Utama

Pada Gambar 6 menampilkan Menu Belajar. terdapat tiga tampilan yaitu belajar hijaiyah, belajar harokat dan belajar tanwin. untuk mememilih menu belajar maka dapat memulai pembelajaran tentang huruf hijaiyah, harokat dan tanwin. 




Gambar 7. Tampilan Menu Kuis

Pada Gambar 7 menampilkan Menu Kuis. terdapat empat tampilan yaitu tebak hijaiyah, tebak harokat, tebak tanwin dan tebak bacaan. untuk mememilih menu kuis maka akan terdapat soal soal yang berkaitan tentang huruf hijaiyah tanda baca serta tebak bacaannya.

\section{SIMPULAN}

Berdasarkan hasil dari pembahasan yang telah diuraikan pada bab sebelumnya dan menyesuaikan dari rumusan masalah yang ada, maka kesimpulan yang diperoleh peneliti adalah yaitu aplikasi pembelajaran dapat memudahkan murid murid Tk untuk mengenal huruf hijaiyah beserta tanda bacanya, aplikasi pembelajaran dapat memudahkan pengguna dalam mengerti dan memahami kata dengan tampilan yang interaktif, proses pembelajaran yang mudah serta menampilkan rincian cara pengoperasiannya, aplikasi pembelajaran dapat memudahkan guru dalam mengajarkan murid agar menumbuhkan minat murid dalam belajar bahasa arab.

\section{DAFTAR PUSTAKA}

Andi, J. (2015). Pembangunan Aplikasi Child Tracker Berbasis Assisted - Global Positioning System ( A-GPS ) Dengan Platform Android. Jurnal Ilmiah Komputer Dan Informatika (KOMPUTA), 1(1), 1-8.

Dani, R., Sugiharto, A., \& Winara, G. A. (2015). Aplikasi Pengolahan Citra Dalam Pengenalan Pola Huruf Ngalagena Menggunakan MATLAB. Konferensi Nasional Sistem \& Informatika.

Dimyati, M. dan. (2013). Model-model pengajaran dan pembelajaran. Teaching and Educations.

Fadly, M., Suhendro, D., \& Syahputra, A. (2019). Perancangan Aplikasi Persediaan Barang dan Bahan Makanan Menggunakan Metode FIFO pada KFC Pematangsiantar. Jurnal Ilmiah Media Sisfo, 13(1), 48. https://doi.org/10.33998/mediasisfo.2019.13.1.527

Gunawan, W. (2019). PENGEMBANGAN APLIKASI BERBASIS ANDROID UNTUK PENGENALAN HURUF HIJAIYAH. Jurnal Informatika. https://doi.org/10.31311/ji.v6i1.5373

Paraya, G. R., \& Tanone, R. (2018). Penerapan Firebase Realtime Database Pada Prototype Aplikasi Pemesanan Makanan Berbasis Android. Jurnal Teknik Informatika Dan Sistem Informasi, 4(3), $397-406$. https://doi.org/10.28932/jutisi.v4i3.870

Pebriani. (2012). Peningkatan Kemampuan Anak Mengenal Huruf melalui Permainan Menguraikan Kata di Taman Kanak-Kanak Negeri Pembina Agama. Jurnal Pesona PAUD.

Pramana, H. W. (2012). Aplikasi Inventory Berbasis Access 2003. Jakarta: PT. Elex Media Komputindo.

Rosa A.S, and M. S. (2011). Modul Pembelajaran Rekayasa Perangkat Lunak (Terstruktur dan Berorientasi Obyek). In Bandung: Modula. https://doi.org/10.1017/CBO9781107415324.004

Safaat, N. (2011). Pemrograman Aplikasi Mobile Smartphone dan Tablet PC Berbasis Android. Bandung: Informatika Bandung. In Android. 